\title{
Benefits of Sebastiania hispida (Euphorbiaceae) extract and photobiomodulation therapy as potentially adjunctive strategies to be explored against snake envenoming
}

\author{
Doroty Mesquita Dourado ${ }^{1,2,8}\left([) \cdot\right.$ Rosemary Matias $^{3} \oplus \cdot$ Baldomero Antonio Kato da Silva $^{4}(\mathbb{0} \cdot$ \\ Fiorela Faria Milanesi ${ }^{5}$ (D) Mayra Duarte Martello ${ }^{6}$ (D) Carlos Henrique Marques dos Santos ${ }^{1}$. \\ Claudia Andréa Lima Cardoso ${ }^{7}$ (D) Willians Fernando Vieira ${ }^{8}$ (D) $\cdot$ Maria Alice da Cruz-Höfling ${ }^{8}$ (i)
}

Received: 16 March 2021 / Accepted: 26 July 2021 / Published online: 2 August 2021

(c) The Author(s), under exclusive licence to European Photochemistry Association, European Society for Photobiology 2021

\begin{abstract}
The purpose of this study was to assess the topic use of Sebastiania hispida extract and low-level gallium-arsenide laser irradiation (GaAs, $904 \mathrm{~nm}$ ) to reduce the local myonecrosis and edema of Bothrops moojeni snake venom-injected gastrocnemius. Wistar rats receiving intramuscular venom injection ( $\mathrm{VBm}$ ) were compared with saline control (S) and envenomed rats receiving local exposure to plant extract (VExt) or laser irradiation (VL). The phytochemistry and thin-layer chromatography of S. hispida extract indicated the presence of phenolic compounds like gallic acid and flavonoids including quercetin. Gastrocnemius of VExt and VL groups had a significant reduction of edema and creatine kinase (CK) activities and a greater Myogenin (MyoG) expression compared to VBm group, with the plant extract efficacy better than laser exposure. Reduction of edema and serum CK activities reflects a lessening of muscle damage, whereas the increase of MyoG indicates myoblast differentiation and acceleration of muscle repair. The S. hispida richness in phenolic compounds and flavonoids, such as the light modulatory ability to triggering a multitude of cell signalings likely underlie the positive outcomes. Our findings suggest both treatments as potential auxiliary tools to be explored in clinical trials in combination with anti-venom therapy after Bothropic snakebites.
\end{abstract}

Keywords Snake envenomation · Complementary therapies $\cdot$ Skeletal muscle regeneration $\cdot$ Gallium-arsenide (GaAs) laser $\cdot$ Photobiomodulation

\section{Introduction}

Snake envenoming is a serious public health problem worldwide $[1,2]$ that has been considered by the World Health Organization [3] a neglected tropical disease. Epidemiological and clinical reports indicate rural communities in tropical developing countries as the most vulnerable [4]. In Latin America, the majority of accidents are caused by Viperidae snakes mainly those belonging to the Bothrops genus [5]. In Brazil, the state of Mato Grosso do Sul (MS) has a high rate of ophidian accidents caused by Bothrops spp. [6], including Bothrops moojeni [7].

Baldomero Antonio Kato da Silva

baldomero@ufpi.edu.br

Extended author information available on the last page of the article
Clinical manifestations of envenomation may vary depending on the species, their nutritional state, age, geographical habitat [8], amount of venom inoculated, body region affected, and time elapsed to receive specific treatment [9], and the health condition of the victim. However, all of the clinical manifestations share the development of acute inflammatory reaction that curse with local and systemic effects; in addition, pro- and antiinflammatory cytokines and second messengers such as nitric oxide (NO) mediate molecular events as a consequence of envenoming [10-12]. Interestingly, the same molecular events trigger the activation of satellite cells viewing tissue damage repair [13]. In general, legs and arms are the most affected by snakebites with skeletal muscle tissue the main targets of venom-containing toxins. Serum therapy is traditionally used for neutralizing systemic alterations but display no effectiveness against local damage caused by snakebite [14]. Phospholipases 
$\mathrm{A}_{2}\left(\mathrm{PLA}_{2}\right)$ myotoxins, such as Lys49 $\mathrm{PLA}_{2}$ homologue and Asp49 PLA $\mathrm{P}_{2}$ and blood disturbance enzymes contained in venom rapidly disseminate and cause fast destruction of soft tissues before victims can reach clinical support [15-17]. A syndromic set of molecular and cellular alterations starting with $\mathrm{PLA}_{2}$-induced rupture of cell membrane are activated producing pain, thrombolysis, blood incoagulability, local anoxia, oxidative stress, edema, and myonecrosis, whose severity may result in permanent sequelae and even amputation of the envenomed member [18]. Complementary therapies urge to be explored in order to minimize the exacerbation of local muscle destruction.

An important strategy to explore is the use of plants for the medicinal treatment of venomous snakebites [19]. In remote regions of the planet healing plants were long used to treat a variety of diseases based on ancient traditions whose knowledge passes across generations. Actually, folk tradition-based medicinal plants prospection has been a permanent area of pharmaceutical interest [20, 21] aiming at identifying molecules with pharmacological therapeutic potential. Plants are rich source of bioactive compounds with high action spectrum [22]. Sebastiania hispida (Mart.) Pax (Euphorbiaceae) is a native species of the Cerrado bioma characteristic of semi-flooded fields at the Brazilian Pantanal and that has been described as possessing a significant anti-inflammatory potential [23-25].

Another great therapeutic potential has been given to the photobiomodulation therapy (PBMT), especially by low-energy laser irradiation. Studies have shown that PBMT promotes pain relief, stem cells activation, cell proliferation, protein synthesis, angiogenesis, tissue repair, and anti-inflammatory, anti-apoptotic and antioxidant activities [26-29]. The so great kind of cellular events activated by PBMT stimulated the assessment of its use to neutralizing local effects at the site of snake bitten. In fact, a growing number of experimental studies have lately enlightened the positive effects of PBMT on muscle tissue that were damaged by snake venom [30-38].

Based on all considerations exposed above, the purpose of this study is to examine the benefits of two complementary approaches that likely could represent a kind of integrative therapy to be explored as adjunctive to anti-ophidian serum therapy by medical practitioners. For the local phytotherapy we used $S$. hispida-derived hydro-methanolic (hydro-MeOH) extract, whereas for PBMT we used the low-energy gallium-arsenide (GaAs) semiconductor diode laser irradiation $(904 \mathrm{~nm})+$ to assess the recovery of skeletal muscle from $B$. moojeni snake venom-induced myonecrosis, inflammation and perfusion deprivation. A brief discussion about the mechanisms underlying the two alternative approaches is presented.

\section{Materials and methods}

\subsection{Plant collection, identification and extract preparation}

The aerial parts (leaves and stems) of adult plants of $S$. hispida (Euphorbiaceae) were collected in the municipality of Aquidauana, Pantanal, MS, Brazil (19 $30^{\prime} 18^{\prime \prime}$; $\left.55^{\circ} 36^{\prime} 45^{\prime \prime} \mathrm{W}\right)$. The plant was identified by the Botanist Eloty Justina Dias Schleder, Ms. Science in Regional Environment and Development (Anhanguera-Uniderp University). The Genetic Heritage Management Council (CGen) from the Brazilian Ministry of Environment that regulates the access to genetic resources and traditional knowledge through the Provisional Measure number 2186-16/2001 authorized the plant collection for research purposes under the registration number $010579 / 2013-3$. A voucher specimen (number 7765) was deposited in the Herbarium of the Botany Department at the Anhanguera-Uniderp University. S. hispida aerial parts were dried in an air circulation oven $\left(40^{\circ} \mathrm{C}\right)$, fragmented and grounded in an electric mill. The powder was submitted to extraction with methanol $(\mathrm{MeOH})$ by static maceration $\left(28 \pm 3{ }^{\circ} \mathrm{C}\right)$, followed by filtration and solvent elimination in a rotary evaporator $\left(\right.$ Tecnal ${ }^{\circledR}$, model MA120, Brazil) to obtaining the crude methanolic extract $(\mathrm{MeOH})$. Subsequently, a part of the $\mathrm{MeOH}$ extract $(100 \mathrm{~g})$ was suspended in distilled/deionized water $(1000 \mathrm{~mL})$ to obtain the hydro-MeOH extract at a concentration of $0.1 \mathrm{mg} / \mathrm{mL}$. Both $\mathrm{MeOH}$ and hydro$\mathrm{MeOH}$ extracts were stored under refrigeration $\left(4 \pm 1^{\circ} \mathrm{C}\right)$.

\subsection{Phytochemical analysis}

The $\mathrm{MeOH}$ and hydro- $\mathrm{MeOH}$ extracts were submitted to classical phytochemical analysis, according to the protocol described by Harborne [39]. Analyses were conducted in triplicate, and color change and precipitate formation were observed. In terms of intensity, the score of readings was represented as follows: negative $(-)$, partial $( \pm)$, low $(+)$, partially moderate $(++)$, moderate $( \pm++)$ and high intensity $(+++)$, conducted in frequencies of $0,10,25$, 50,75 and $100 \%$, respectively, according to Fontoura et al. [40]. The afrosimetric index and the content of total and insoluble ashes were also determined with the aid of the Brazilian Pharmacopoeia [41].

To quantify the total phenols of $\mathrm{MeOH}$ and hydro$\mathrm{MeOH}$ extracts, the Folin-Ciocalteu (F-C) method [42] was applied and the gallic acid $\left(10-350 \mathrm{mg} \mathrm{g}^{-1}\right)$ was used as standard $\left(y=0.0040+0.03683 x ; r^{2}=0.9987\right)$. Flavonoids were determined by the aluminum chloride method, according to Do et al. [43], and quercetin was used as 
standard $\left(y=0.0209+0.02783 x ; r^{2}=0.9993\right)$. In addition, the $\mathrm{MeOH}$ and hydro-MeOH extracts of the aerial parts of $S$. hispida were used to determine the total phenolic compounds and flavonoids content and their antioxidant activity.

\subsection{Thin-layer chromatography (TLC) analysis of the $\mathrm{MeOH}$ and hydro-MeOH extracts and high performance liquid chromatography (HPLC)}

The confirmatory analysis of classes of chemicals present in the $\mathrm{MeOH}$ and hydro-MeOH extracts was performed using TLC to verify the presence of quercetin and rutin (flavonoids), and gallic acid (phenolic compound). Eluent systems, visualization of the bands (ultraviolet light irradiation: 254 and $365 \mathrm{~nm}$ ), and developers were set based on Bladt and Zgainski [44] and TLC was observed under a UV lamp (254 and $365 \mathrm{~nm}$ ) and visualized using NP/PEG reagent (diphenylboric acid 2-aminoethyl ester/polyethylene glycol) under $365 \mathrm{~nm}$ [45]. The retention factors (Rf) of the bands formed in the areas of the chromatographic band patterns and the obtained from the $\mathrm{MeOH}$ and hydro- $\mathrm{MeOH}$ extracts were calculated.

The HPLC method (Varian Prostar 210 Pump HPLC System, Agilent Technologies ${ }^{\circledR}$, CA, USA) was performed to confirm the chemical substances in the $\mathrm{MeOH}$ extract. A ternary solvent delivery system, equipped with an auto sampler and a photodiode array (PDA) detector was used. The Star WS software (Star Chromatography Workstation Version 6.41, Varian Inc., CA, USA) was used for chromatograms and for measuring peak areas. HPLC column was a RP18 $(25 \mathrm{~cm} \times 4.6 \mathrm{~mm} \times 5 \mu \mathrm{m})$ reversed-phase column, with a small precolumn $(2.5 \mathrm{~cm} \times 3 \mathrm{~mm})$ containing the same packing used to protect the analytical column. Elution was carried out with a gradient solvent program of methanol:water:acetonitrile (40:50:10) taking $40 \mathrm{~min}$ to reach $80 \%$ methanol, $10 \%$ water and $10 \%$ acetonitrile, returning to the initial conditions in $20 \mathrm{~min}$ after that. The flow rate was set at $1.0 \mathrm{~mL} / \mathrm{min}$ and the volume injected was $50 \mu \mathrm{L}$. All chromatographic analyses were performed at $22{ }^{\circ} \mathrm{C}$.

\subsection{Venom}

The pooled crude venom was harvested from adult male Bothrops moojeni (Hoge; Viperidae) snakes captured in the Pantanal region, from the same area that plants of S. hispida were collected (municipality of Aquidauana, Pantanal, MS, Brazil; 19 $30^{\prime} 18^{\prime \prime} \mathrm{S}, 5^{\circ} 36^{\prime} 45^{\prime \prime} \mathrm{W}$ ). The pooled venom samples were extracted, lyophilized and subsequently stored at $4{ }^{\circ} \mathrm{C}$. The $B$. moojeni venom concentration/dose was $40 \mu \mathrm{g} \mathrm{mL}{ }^{-1}(0.4 \mathrm{mg} / \mathrm{kg})$ diluted in sterile saline solution $(0.9 \% \mathrm{NaCl})$ just prior the intramuscular (i.m.) injection.

\subsection{Animals and ethics statement}

All in vivo experiments were approved by the Institutional Committee for Ethics in Animal Use (CEUA/IB/UNICAMP, protocol number 2757-1), and were carried out according to the established by the Brazilian National Council for Animal Experimentation Control (CONCEA), the Brazilian College of Animal Experimentation (COBEA) recommendations, and the National Institutes of Health guide for the care and use of Laboratory animals (NIH Publications No. 8023, revised 1978). ARRIVE guidelines were followed.

Adult male Wistar rats (Rattus norvegicus) weighing 200-300 g, 8-10-week-old, were obtained from the Multidisciplinary Center for Biological Investigation at the University of Campinas (CEMIB/UNICAMP). The animals were housed individually in plastic cages in a temperatureand humidity-controlled room $\left(22 \pm 2{ }^{\circ} \mathrm{C} ; 50-60 \%\right.$; respectively) and standard $12 / 12 \mathrm{~h}$ dark/light cycle with food and water ad libitum.

\subsection{Complementary treatment protocols}

Rats were randomly divided into four experimental groups and identified as follows: (1) S (saline; control group): Injected with sterile saline solution $(0.9 \% \mathrm{NaCl}$; i.m.); (2) VBm (B. moojeni venom group): Injected with B. moojeni snake venom (40 $\mu \mathrm{g} \mathrm{mL}^{-1}$; i.m.); (3) VExt (venom plus $S$. hispida extract group): Injected with $B$. moojeni venom (40 $\mu \mathrm{g} \mathrm{mL}^{-1}$; i.m.) followed by the hydro-MeOH extract $(0.1 \mathrm{mg} / \mathrm{mL})$ of $S$. hispida (leaves and stems) treatment, topically administered; (4) VL (venom plus PBMT group): Injected with $B$. moojeni snake venom $\left(40 \mu \mathrm{g} \mathrm{mL}^{-1}\right.$; i.m.) followed by PBMT exposure (GaAs, $904 \mathrm{~nm}$ laser irradiation). For all experimental groups, the animals ( $n=120$ total; $n=30$ /group; $n=5 /$ time interval) were euthanized at 3,24 and $48 \mathrm{~h}$ and 3, 7, 14 days after saline or venom injection (detailed in Sects. 2.6.1 and 2.6.2 topics). After a preliminary set of experiments to identify the phytochemical profile of $\mathrm{MeOH}$ and hydro-MeOH extracts, the latter was elected to be used because abundant in phenols and flavonoids, solubility and, in general, less toxicity.

\subsubsection{S. hispida extract treatment protocol}

By gentle handling, trichotomy and asepsis of right hindlimb, the exposed belly region of right rats' gastrocnemius was i.m. injected with $40 \mu \mathrm{g} \mathrm{mL}^{-1}(0.4 \mathrm{mg} / \mathrm{kg})$ venom diluted in $0.9 \%$ sterile saline solution. Soon after venom injection, the $S$. hispida hydro-MeOH extract $(0.1 \mathrm{mg} / \mathrm{mL})$ was spread evenly on the skin surface just at the region injected with venom with the help of a spatula. Topical treatment was done daily (during 14 days), at 9:00 to 10:00 a.m.; animals euthanized at $3,24,48 \mathrm{~h}$ and at 3,7 and 14 days 
received 1, 2, 3, 4, 8 and 15 times of extract topic exposure, respectively ( $n=5$ per time interval). The 15 th extract exposure occurred $1 \mathrm{~h}$ prior euthanasia.

\subsubsection{Photobiomodulation therapy (PBMT) protocol}

For PBMT sessions, we used an infrared Class-III galliumarsenide active medium (GaAs) semiconductor diode laser (Photon Laser III DMC ${ }^{\circledR}$, São Carlos, SP, Brazil), recording at the near-infrared (NIR) light spectrum (904 nm). PBMT sessions were performed once a day, from 9:00 to 10:00 a.m., during 14 days. Parameters described in Table 1 were based on previous studies performed by Mester et al. [46] and Basford [47, 48].

For rats' contention, we used a plastic tube with a window that allowed access to the gastrocnemius-envenomed site. The irradiation incidence was perpendicular to the gastrocnemius muscle fibers alignment, and $1 \mathrm{~cm}$ far from the shaved skin and injection site. That configuration allowed the infrared light of the laser probe to be delivered transcutaneously straight onto the site of gastrocnemius where B. moojeni snake venom or saline injections was delivered. Animals were exposed to PBMT sessions after the following experimental periods: 3,24 , and $48 \mathrm{~h}(1,2$, and 3 cumulative laser irradiation sessions, respectively); 3,7 , and 14 days (4, 8 , and 15 cumulative laser irradiation sessions); last PBMT session was performed $1 \mathrm{~h}$ before euthanasia.

\subsection{Edematogenic activity (EA) and creatine kinase (CK) activity}

After the periods of 3,24, $48 \mathrm{~h}$ and 3, 7 and 14 days of the experiment, the rats were euthanized by an intraperitoneal (i.p.) injection of 1:1 xylazine (5 mg/kg): ketamine (30 mg/ kg) (Vetbrands Brasil Ltda, Jacareí, SP, Brazil). Gastrocnemius muscle was removed by cutting off its insertion to tendons and then the muscle was weighed. For the measurement of the EA just an $8 \mathrm{~mm}$-sized medial portion of the muscles having centralized the site of saline or venom injection were considered ( $n=5$ per time interval). The quantification of edema was calculated from the average weight of the control group (S) and percentage variation between the mean weight of gastrocnemius from each experimental group (VBm, VExt, VL).

Determination of myonecrosis was assessed by measuring serum CK activity (and morphological analysis, see
Sect. 2.8 below) at each time frame post saline or venom administration (S and VBm groups, respectively), or after topic treatment with $S$. hispida extract or PBMT (VExt and VL groups) ( $n=5 /$ time). Samples were collected by cardiac puncture directly into heparin-containing tubes. After collected, the blood samples were immediately centrifuged (2000 r.p.m./25 min) to the blood serum separation. The levels of CK were determined using a CK-NAK kit (Wienner Lab., Rosário, Argentina), according to the manufacturer specifications. The values were expressed in units/liter (U/L).

\subsection{Morphology and immunohistochemistry (IHC) of myogenin (MyoG)}

For morphological studies, the selected medial part of gastrocnemius from groups (S, VBm, VExt, and VL) was fixed in $10 \%$ formaldehyde and then processed for paraffin embedding, cross-sectioning and double staining with hematoxylin/eosin (H\&E). Paraffin sections were 5- $\mu \mathrm{m}$-thick for both morphology and IHC assays.

For IHC, the selected medial part of gastrocnemius from $\mathrm{S}, \mathrm{VBm}, \mathrm{VExt}$, and VL groups were fixed in $4 \%$ paraformaldehyde (PFA) and then processed for paraffin embedding and quantification of the MyoG-immunolabeled cells, as a marker of myogenesis activation. For MyoG, just 3 and 7-day-intervals were selected for immunolabeling due to the representation of proliferation of quiescent satellite (3 days) and initiation of differentiation (7 days) [13]. After dewaxing and processing, $5-\mu \mathrm{m}$-thick muscle sections were rinsed in phosphate-buffered saline (PBS) and endogenous peroxidase was inactivated with $3 \% \mathrm{H}_{2} \mathrm{O}_{2}$ diluted in $0.1 \mathrm{M} \mathrm{PBS}(\mathrm{pH} 7.0$ ) and then washed again and incubated with a specific primary antibody (Anti-Myogenin 5FD; 1:50; code 12,732; Santa Cruz Biotechnology Inc., CA, USA) in PBS for 30 min at 37 ${ }^{\circ} \mathrm{C}$ followed by an overnight period at $4{ }^{\circ} \mathrm{C}$. Once completed the overnight period, the slides were washed and incubated with a biotinylated anti-goat or anti-swine secondary antibody (EnVision-HRP link, Dako Cytomation, CA, USA) for $30 \mathrm{~min}$. After the slides were washed in PBS and the Advanced ${ }^{\mathrm{TM}}$ HRP enzyme was applied for $30 \mathrm{~min}$ and, finally, the chromogenic substrate plus 3,3'-diaminobenzidine (DABp, DakoCytomation) for $1 \mathrm{~min}$. The counterstaining was performed with hematoxylin, for $30 \mathrm{~s}$. The negative control was obtained by omitting the primary antibody. The quantification of the $\mathrm{MyoG}$ expression was performed by

Table 1 Laser parameters used

\begin{tabular}{lllllllll}
\hline Laser & $\lambda$ & Power $(\mathrm{mW})$ & Spot size $\left(\mathrm{cm}^{2}\right)$ & PD $\left(\mathrm{mW} / \mathrm{cm}^{2}\right)$ & Energy $(\mathrm{J})$ & ED $\left(\mathrm{J} / \mathrm{cm}^{2}\right)$ & Frequency $(\mathrm{Hz})$ & Time $(\mathrm{s})$ \\
\hline GaAs & 904 & 35 & 0.16 & 0.21 & 0.04 & 4 & 10,000 & 18 \\
\hline
\end{tabular}

$\lambda$ wavelength (nm); $P D$ power density; $E D$ energy density 
counting the immunolabeled cells in a total of 10 fields per animal muscle. Images were obtained with a video camera (Samsung ${ }^{\circledR}$ ) coupled to a Bioval ${ }^{\circledR}$ L2000C light microscope, with aid of the ImageLab program version 2.4.

\subsection{Statistical analysis}

Data were expressed as mean \pm standard deviation (SD). For comparison between groups was used the Kruskal-Wallis test, and where applicable, the post-hoc test of Dunn. Comparative differences with $p<0.05$ were considered significant.

\section{Results and discussion}

\subsection{Phytochemical analysis of S. hispida methanolic (MeOH) and hydro-methanolic (hydro-MeOH) extracts}

Phytochemical screening of the $\mathrm{MeOH}$ and hydro-MeOH extracts $(0.1 \mathrm{mg} / \mathrm{mL})$ of $S$. hispida indicated the presence of phenolic compounds, tannins, flavonoids, anthraquinones, flavonols, steroids, saponins, reducing sugars, and triterpenes. Both extracts ( $\mathrm{MeOH}$ and hydro- $\mathrm{MeOH}$ ) showed the same frequency for phenolic compounds (around 100\%); tannins, flavonoids, saponins and reducing sugars were higher in the hydro-MeOH extract, insofar anthraquinones, flavonols, steroids and triterpenes were higher in the $\mathrm{MeOH}$ extract, as shown in Fig. 1A. These results were confirmed by analysis of the chromatographic profile in the HPLC of the $\mathrm{MeOH}$ extract, using gradient analysis conditions and two wavelengths ( 254 and $284 \mathrm{~nm}$ ). These two monitored wavelengths suggest the presence of benzopyran skeleton, which has a flavonoid characteristic. From the profiles obtained from the HPLC analysis, the hydro- $\mathrm{MeOH}$ extract presents very polar substances, probably glycoflavonoids, as shown in Fig. 1B. The extraction method prepared with $\mathrm{MeOH}: \mathrm{H}_{2} \mathrm{O}$ retains most of the biological activity of a plant sample owing to plant glycoflavonoids and tannins or other highly polar compounds, such as saponins and reducing sugars, detected more frequently in the hydro-MeOH extract (Fig. 1A).

These results have great similarity in terms of the chemical constituent to the specimens of $S$. hispida collected in other regions of the Brazilian Cerrado [24, 25], except for the saponins, anthraquinones, steroids and reducing sugars (Fig. 1A).

Differences in phytochemical content between same plant species but living in different regions are a consequence of environmental factors, such weather conditions, seasonality, soil type, altitude and plant genetic or epigenetic variability. In addition, other factors like interactions between neighboring plants including competing plants and parasitic angiosperms as well as herbivorous animals such as insects, nematodes, pathogens and parasites namely bacteria, fungi, viruses, or allies (symbiotic bacteria and fungi) have influence in the properties of plant material obtained from wild and/or cultivated specimens $[19,49]$.

The separation of components from $\mathrm{MeOH}$ and hydro$\mathrm{MeOH}$ extracts was achieved by thin layer chromatography (TLC), and the results of these analyses revealed the presence of quercetin and gallic acid in both extracts. The occurrence of other bands showed the presence of phenols and flavonoids, as depicted in Table 2. By scanning with a spectrum with better resolution, we observed the presence of flavonoids as the most relevant chromophore in both extracts. The extracts are strongly absorbed in the wavelength range of $260-400 \mathrm{~nm}$ (see Table 2) and are in line with the mean values of total phenols and flavonoids, which were significantly expressive for both hydro-MeOH and $\mathrm{MeOH}$ extracts. Thus, because of the high concentration of polyphenols (phenolic and flavonoids compounds) and greater polarity, the $S$. hispida hydro-MeOH extract was selected for the treatment of B. moojeni-induced edema and myonecrosis in rats' gastrocnemius, which proved to be a promising candidate for the development of water-soluble healing drugs. In agreement, it was recently described that ethanol-based extract (EtOH-based) hydrogel formulation of S. hispida sprouts used as a complementary therapy for the closure of wounds infected with Staphylococcus aureus [25].

\subsection{Clinical evaluation of B. moojeni venom i.m.-injected rats}

We observed that rats from VBm group presented a reduced exploratory activity, especially at the first experimental periods (3, 24 and $48 \mathrm{~h}$ ), which otherwise would be characteristic of healthy rats inside their cages. In general, rats from VExt group showed a better health condition in comparison to rats from $\mathrm{VBm}$ group, including a higher interest for food; rats from VBm group showed increased levels of water intake than other groups, especially at the first periods of experimentation. In addition, the dissected-medial part of the gastrocnemius from VBm group showed a brownish coloration and seemed more voluminous than the gastrocnemius of the saline group ( $\mathrm{S}$; control) (data not shown).

\subsection{Edematogenic activity (EA) and creatine kinase (CK) activity}

Figure $2 \mathrm{~A}$ shows that at 3 and $24 \mathrm{~h}$ post i.m. venom administration there was no increase in the muscle weight relative to the saline group (S; control), thus indicating a lack of EA in the envenomed gastrocnemius (VBm group). Curiously, at same $24 \mathrm{~h}$ time-point there was a significant gain 
Fig. 1 HPLC phytochemical analyses of $S$. hispida hydromethanolic (hydro-MeOH) and methanolic $(\mathrm{MeOH})$ extracts. A Class and intensity (\%) of secondary metabolites from the hydro-MeOH (grey bars) and $\mathrm{MeOH}$ (black bars) extracts. B Representative chromatographic profile of the hydro- $\mathrm{MeOH}$ extract obtained from aerial parts of S. hispida, Aquidauana, Pantanal, MS, Brazil. $(\lambda=284 \mathrm{~nm})$
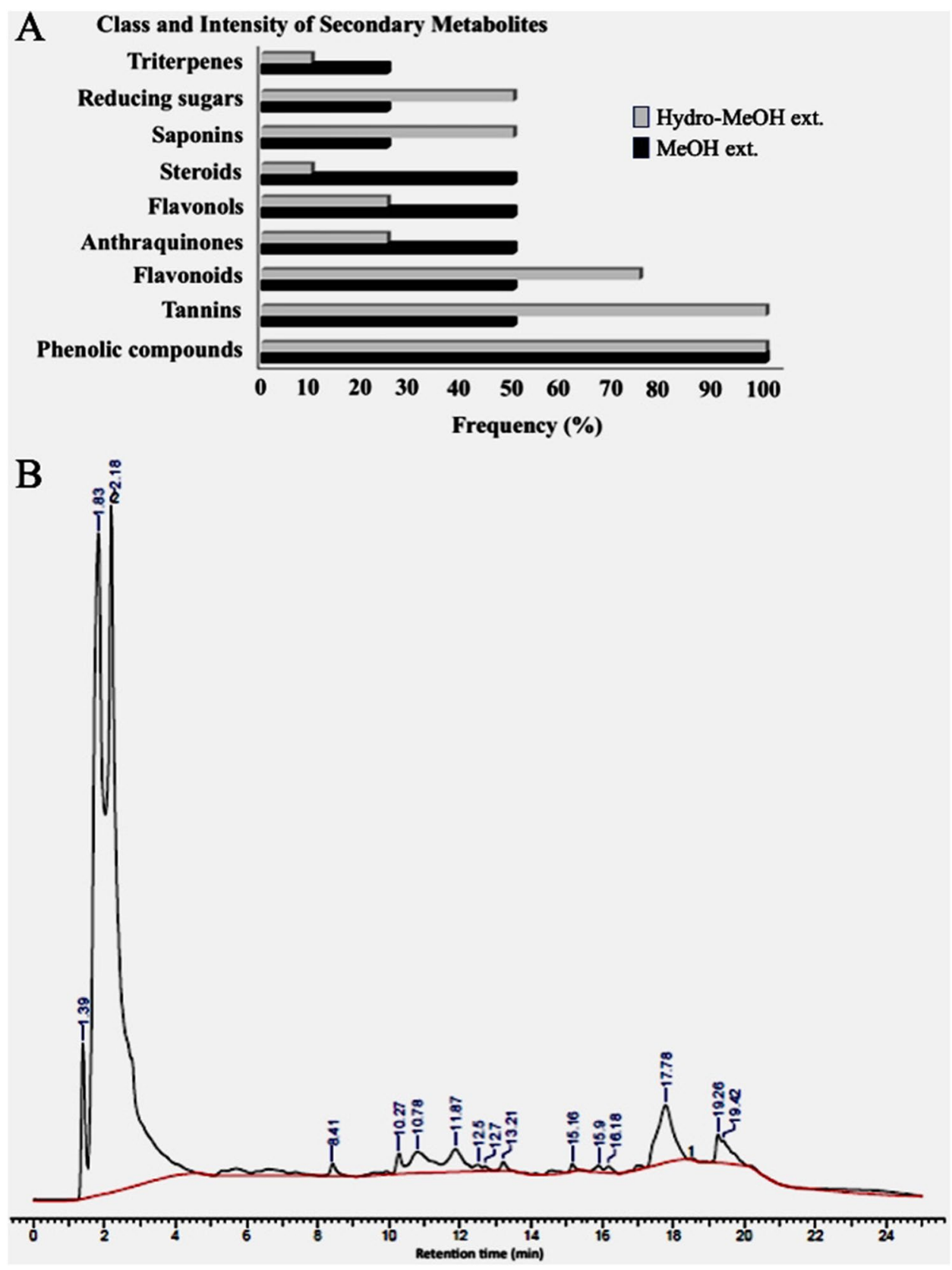

of weight in envenomed muscles exposed twice to topic $S$. hispida extract (VExt group) or submitted twice to PBMT (VL group) with the latter more edema-forming than the former $(p<0.05)$. It was suggested that manipulation of animals' injured right hindlimb during the treatments could be a likely consequence of edema induction. From $48 \mathrm{~h}$ till 14 days post venom injection there was significant $\mathrm{VBm}$ muscle weight gain thus indicating the onset of vascular leakage and plasma extravasation and consequent edema formation likely mediated by inflammatory mediators [50]. The highest EA caused by the snake venom was found at $48 \mathrm{~h}$ and the least at 14 days, meaning that auto-regulatory mechanisms were triggered to restore muscle homeostasis.
The daily topic treatment at the site of venom injection with the hydro-MeOH extract of the aerial parts of $S$. hispida or through PBMT prevented significantly the EA that caused by $B$. moojeni snake venom from $48 \mathrm{~h}$ till 14 days, thus suggesting a positive modulatory action of both the plant extract and the light energy on the inflammatory mediators. The plant extract showed better efficacy than PBMT to counteract the formation of edema caused by the venom effect. Nevertheless, it is elusive whether such better performance of the plant extract relative to PBMT would be pharmacological in nature or either a consequence of the gentle spread of hydro- $\mathrm{MeOH}$ extract onto the surface of the right versus the more drastic handling of the animals' leg into the tube 
Table 2 Results of thin layer chromatography (TLC), retention factor, eluents, developers, UV-visible scanning spectra and content of total phenols (TP) and flavonoids (F) for both hydro-methanolic (hydro-

\begin{tabular}{|c|c|c|c|c|c|c|c|}
\hline Ext & Pattern & Revel & Rf. standard & Rf. sample & Sample $\lambda_{\max }(\mathrm{nm})$ & $\mathrm{TP}\left(\mathrm{mg} \cdot \mathrm{g}^{-1}\right)$ & $F\left(\mathrm{mg}^{-1}\right)$ \\
\hline \multirow[t]{3}{*}{ Hydro-MeOH } & Querc & NP -PEG & 0.90 & 0.89 & \multirow[t]{3}{*}{$286,340,380,400$} & \multirow[t]{3}{*}{$238.8 \pm 0.9 \mathrm{a}$} & \multirow[t]{3}{*}{$168.6 \pm 1.2 c$} \\
\hline & G. Ac & NP -PEG & 0.86 & 0.85 & & & \\
\hline & Rutin & NP -PEG & 0.79 & $\mathrm{a}$ & & & \\
\hline \multirow[t]{3}{*}{$\mathrm{MeOH}$} & Querc & NP -PEG & 0.90 & 0.90 & \multirow[t]{3}{*}{$280,324,380,400$} & \multirow[t]{3}{*}{$326.24 \pm 1.2 b$} & \multirow[t]{3}{*}{$228.5 \pm 0.8 \mathrm{~d}$} \\
\hline & G. Ac & NP -PEG & 0.86 & 0.85 & & & \\
\hline & Rutin & NP -PEG & 0.79 & a & & & \\
\hline
\end{tabular}

Ext. extract; hydro-MeOH hydro-methanolic; $\mathrm{MeOH}$ methanolic; Revel. revelators; Rf. retention factor; $\lambda_{\max }$ wavelength maximum (nm); Querc. Quercetin; G. Ac. gallic acid; TP total phenols; F flavonoids; NP-PEG diphenylboric acid 2-aminoethyl ester/polyethylene glycol; Eluent butyl alcohol:acetic acid:water $(4: 1: 1)$

Mean \pm SD; $(p<0.01)$; different letters indicate statistic difference

${ }^{a}$ Absence of bands in the region of the undisclosed pattern

contention during irradiation, or both. Concordantly, on the 14th day, S. hispida hydro-MeOH extract sustained the EA reduction, whereas PBMT did not (Fig. 2A). The EA neutralization by both treatments was partial given the gastrocnemius weight of VExt and VL remained significantly different from the muscle weight of $\mathrm{S}$ group $(p<0.05)$. The mechanism by which the $S$. hispida extract and PBMT modulate the inflammatory mediators is a very relevant issue for further investigations.

Figure 2B shows that relative to $S$ group, the VBm group showed an immediate $(3 \mathrm{~h})$ and remarkable rise in the serum CK activity $(p<0.05)$, which was significantly sustained during the whole experimental period, although decreasing in magnitude throughout intervals $(p<0.05)$. This is in line with the fast local myonecrotic changes reported clinically $[5,18]$ and experimentally $[51,52]$ for bothropic accidents. Increased serum CK level is an undebatable evidence of fib-

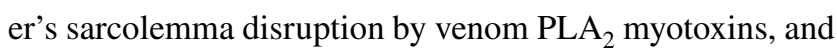
an indication of ongoing fiber necrosis. CK (EC 2.7.3.2) is an enzyme known for playing an important role in the regulation of mitochondria energy metabolism, as it catalyzes the reversible phosphorylation of adenosine diphosphate (ADP) to produce adenosine triphosphate (ATP) [53]. The lack of an energy reservoir for ATP production as a consequence of fiber sarcolemma disruption contributes to the severity of local muscle fibers debacle. For all periods of analysis, CK levels in muscles from treated groups (VExt and VL) were significantly smaller when compared to the VBm group, thus evidencing a protective effect of the S. hispida extract and PBMT daily exposures. Until $48 \mathrm{~h}$ the efficiency in counteracting the venom $\mathrm{CK}$ releasing effect was similar for the S. hispida hydro-MeOH extract and GaAs laser irradiation. However, from 3 to 14 days of treatment, the benefit of plant extract significantly showed superior to the promoted by PBMT in decreasing CK activity; and at days 7 and 14 there were no difference between $\mathrm{CK}$ baseline of $\mathrm{S}$ in relation to
$\mathrm{MeOH})$ and methanolic $(\mathrm{MeOH})$ extracts of the aerial and stem parts of $S$. hispida, Aquidauana, MS, Brazil 

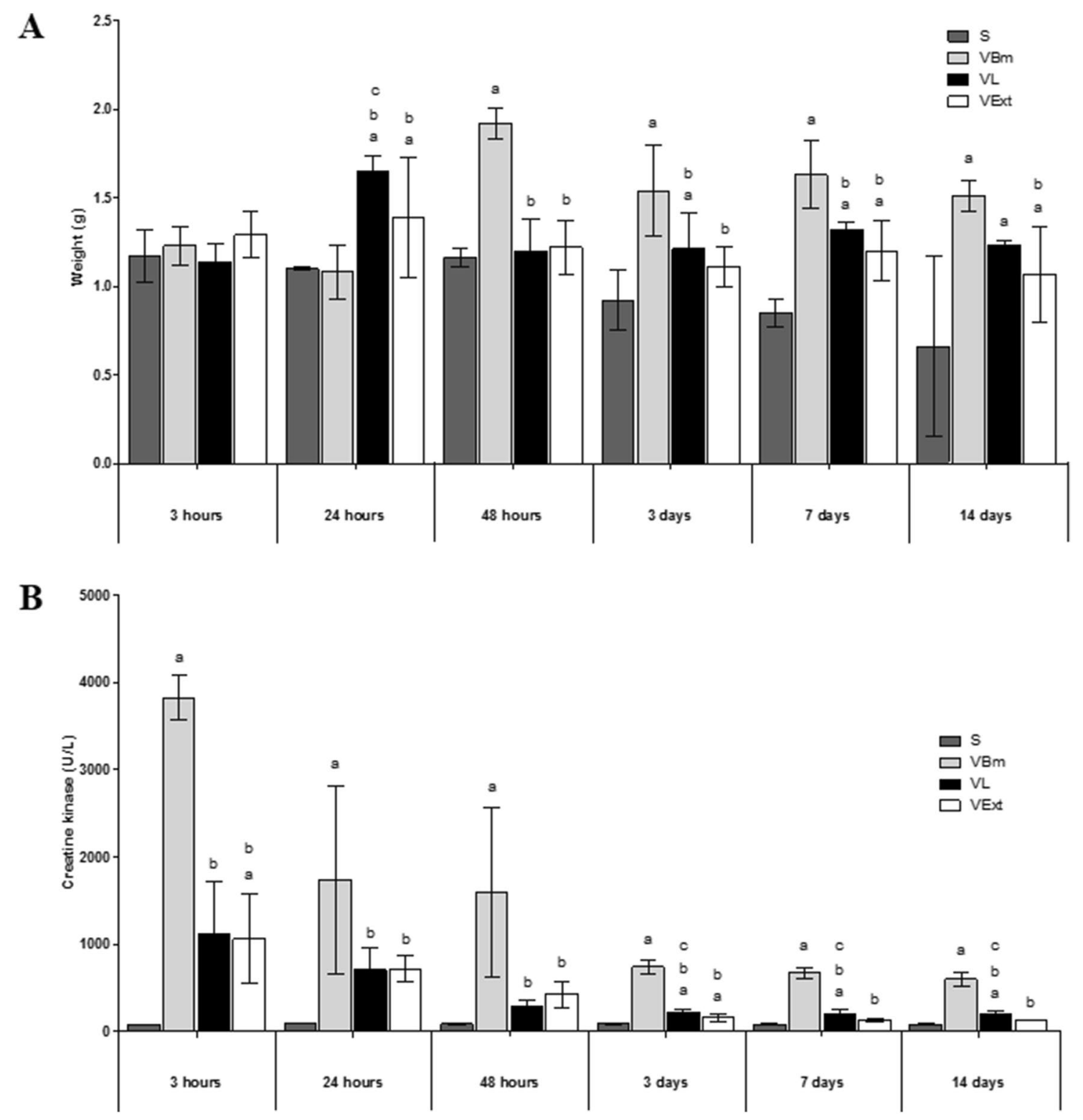

Fig. 2 Edematogenic activity (EA) and Creatine Kinase (CK) activity. A EA activity evaluated by muscle weight (g) at 3, 24, $48 \mathrm{~h}$ and 3,7 , and 14 days after i.m. injection of $B$. moojeni snake venom $(40 \mu \mathrm{g} / \mathrm{mL})$ or saline $(0.9 \% \mathrm{NaCl})$ in the right gastrocnemius muscle, followed by the treatments with S. hispida hydro-MeOH extract or PBMT. B Comparison of the CK activity (U/L) of rats up to 14 days after venom or saline injections. $S$ saline (control group); $V B m$ venom

antiophidic potential. The relationship between the antiophidic activity of phenolic compounds and their derivatives was reported previously [56-58]; studies showed that polyphenols (hydrolysable tannins and phenylpropanoids), including flavonoids, have the capacity of minimizing the tissue oxidative stress and structural damage induced by snake venom [59], which enables tissue faster homeostasis achievement [60]. of Bothrops moojeni; VL venom plus topic PBMT; VExt venom plus topic treatment with $S$. hispida hydro-MeOH extract. "a" means $p<0.05$ in comparison to control group (S); "b" means $p<0.05$ in comparison to venom group (VBm); "c" means $p<0.05$ in comparison to VExt group. Kruskal-Wallis followed by Dunn post hoc test. Data are expressed as mean $\pm \mathrm{SD}$

\subsection{Histopathologic data}

Local tissue injury is a major problem of Bothropic snakes envenoming [51] because specific anti-venom treatment is effective only against the systemic effects. The local degeneration is one of the most notorious aspects of tissue damage and the responsible fact that leads to seque. In many cases, the damage is huge as encompasses also vascular failure and ischemia, which can culminate in the amputation of 
the affected limb $[52,61]$. In the present study, the medial part of the envenomed gastrocnemius from VBm, VExt and VL groups showed macroscopically a dark coloration, with increased volume and necrotic aspects, especially at the first $24 \mathrm{~h}$ after venom exposure, whereas gastrocnemius of the control group (S) showed fresh pink color and healthy appearance (not shown).

The histological examination showed normal morphology of fibers and organized cytoarchitecture of the muscle tissue in the control group (S) at all the time points (not shown). In contrast, myonecrotic myofibers were evident in VBm places reached by the venom. This myolytic action is mainly promoted by myotoxins, such as $\mathrm{PLA}_{2}$ and $\mathrm{PLA}_{2}$ homologues [51, 62], which disrupts sarcolemma and leads to fibers proteolysis through ubiquitin-proteasome system (UPS) activation, as demonstrated by Kenzo-Kagawa et al. [17], in a model of B. jararacussu venom-induced myonecrosis in mice gastrocnemius.
Both the PBMT and $S$. hispida hydro-MeOH extract administration (VL and VExt groups, respectively) neither prevented the tissue acute damage nor the presence of hemorrhage until $48 \mathrm{~h}$ post envenomation. Except for the S group (control; not shown), all the others showed hemorrhage, neutrophils invading the differentially staged myolytic fibers, including round-shaped edematous fibers (Fig. 3A-F).

Although the acute tissue damage at earlier stages post envenomation was not prevented by PBMT, Martin [63] showed that ischemic or poorly perfused tissues as a consequence of microvasculature failure, edema and inflammation have an increased repair response to irradiation by low-intensity laser [32]. This laser-accelerated effect on inflammation reduction and healing is based on several cellular events modulated by PBMT. PBMT-mediated cellular modulation involves stabilization of cell membrane, ATP production and synthesis [64], vasodilation via histamine, $\mathrm{NO}$ and serotonin increases, leukocytic activity, conversion
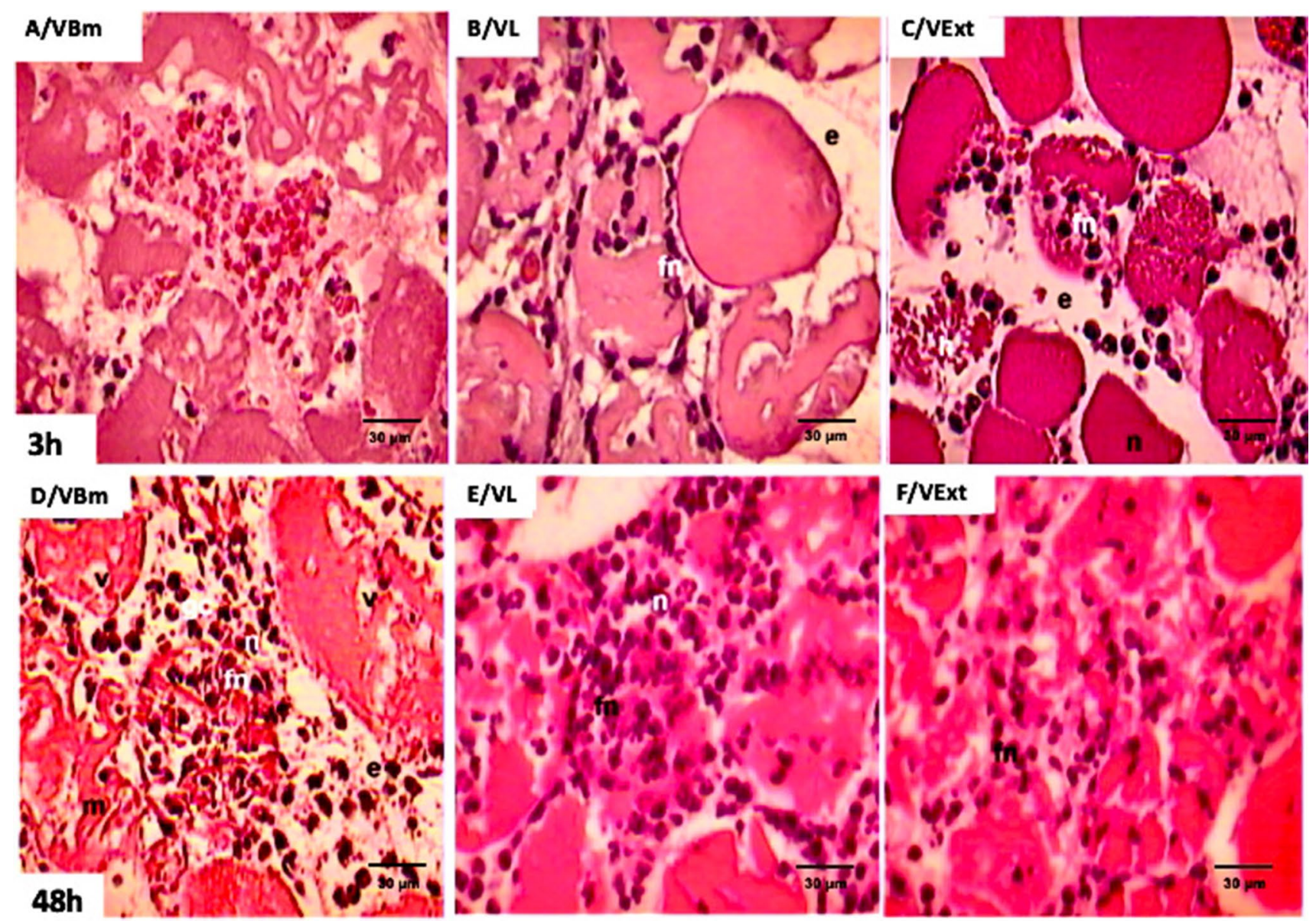

Fig. 3 Light micrographs of rats' gastrocnemius injected with Bothrops moojeni snake venom $(0.4 \mathrm{mg} / \mathrm{kg})$ and exposed to PBMT or $S$. hispida hydro-MeOH extract. A-C transversal section of the gastrocnemius muscle (5- $\mu \mathrm{m}$-thick) at $3 \mathrm{~h}$ after $B$. moojeni venom injection, considering the groups VBm (A), VL (B), and VExt (C). D-F trans- versal section of the gastrocnemius muscle (5- $\mu \mathrm{m}$-thick) at $48 \mathrm{~h}$ after B. moojeni venom injection, considering the groups $\mathrm{VBm}(\mathbf{D}), \mathrm{VL}$ $(\mathbf{E})$, and VExt $(\mathbf{F}) . f n$ fibers with neutrophils; $v$ vacuolation; $e$ edema; $n$ infiltrate of neutrophils; $m$ myonecrosis; $g c$ ghost cells. H\&E; scale bar $=30 \mu \mathrm{m}$ 
of the prostaglandins PGG2 and PGH2 into prostaglandin PGI2, reduction in interleukin 1 (IL-1) and enhanced lymphocyte response [64-68]. Dourado et al. [31] highlighted the positive effects of PBMT through GaAs laser irradiation with light at NIR region $\left(904 \mathrm{~nm} ; 4 \mathrm{~J} / \mathrm{cm}^{2}\right)$ on B. moojeniinduced myonecrosis in mice gastrocnemius, during the first $24 \mathrm{~h}$ post envenoming. The authors observed that PBMT caused a remarkable reduction of CK levels, less congested blood vessels and reduced areas of hemorrhage accompanied by a decrease of damaged muscle fibers. The same PBMT parameters were used by Vieira et al. [37] for treating myonecrosis caused by $B$. jararacussu snake venom injection into mice gastrocnemius. At $72 \mathrm{~h}$ after envenoming, it was observed numerous centrally nucleated fibers indicative of a faster regeneration process induced by PBMT, but like our results, the light therapy did not prevent or reduce the degenerative/catabolic events induced by the venom at the earliest stages. In this sense, neither PBMT nor S. hispida hydro-MeOH extract could prevent the acute venom-induced muscle degradation, but positive results were observed at later intervals meaning improvement of the muscle regenerative process.

On the other hand, the chemical arsenal of constituents in plants makes important therapeutic allies to neutralize snake venom effects [69-72]. In this sense, S. hispida richness in flavonoids and phenolic compounds showed wound healing activity [24], likely based on its antibacterial activity [25]. In the present study model of B. moojeni-induced myonecrosis the partial but effective efficacy of $S$. hispida hydro-MeOH extract might rely on secondary metabolites, flavonoids and tannins, which demonstrated their anti-inflammatory and antioxidant properties [73, 74].

Although the chemical composition of plants is strongly influenced by biotic and abiotic factors [19, 49], it was observed from the phytochemical analysis of S. hispida collected in Campo Grande (MS state) [24, 25] and that of our study collected in Aquidauna city, that there were no changes in the substances content of phenolic and flavonoid compounds, phytomolecules with potential applications such as antimicrobials, antioxidants and other functional activities [23-25], and which may be related to the therapeutic effect evidenced presently.

At day 3, in all the groups (VBm, VL and VExt) the blood vessels were less clogged (not shown) and hemorrhagic foci were no longer detected but a few phagocytic cells persisted to scavenge necrotic remnants (Fig. 4A-C). At this very same interval, myoblasts could already be seen in proliferation together with regenerating central nucleate fibers both in VL group (Fig. 4B) and especially in the VExt group (Fig. 4C) where nuclei with loose euchromatin and prominent nucleolus, is an indication of transcriptionally active fiber engagement (Fig. 4C). At the 7th day, the tissue in VBm was recovering with an evident proliferation of myoblasts (Fig. 4D) whereas comparatively in VL and VExt groups the myogenesis was more advanced as demonstrated by the newly formed central nucleate fibers (Fig. 4E-F). At the 14th day, rounded, bulky young and central-cored fibers were higher in VExt than in VL, which is higher than in VBm (Fig. 4G-I).

\subsection{Immunohistochemistry}

Due to the MyoG importance for the study of the muscle regenerative process, its detection through IHC was performed. MyoG can control the gene transcription and expression of proteins with an important role during myogenesis [75]. Ferri et al. [76] suggest that MyoG expression in the cytoplasm is a mechanism that regulates the protein biological activity and prevents the early differentiation; the migration of MyoG to the nucleus is carried out when the proliferative signals cease and the protein levels significantly increase. The more elevated expressional values were observed by the 3 and 7 days in VExt group, followed by the VL group, as shown in Fig. 5A. MyoG was immunodetected in the myoblasts (Fig. 5B-G). Hydro-MeOH extract showed a tendency to better perform MyoG expression than PBMT, as shown in panel A; panel $\mathrm{G}$ shown numerous centralnucleate regenerated fibers reiterating the best performance of the pant extract.

The study of the mechanism underlying the modulatory action of PBMT and S. hyspida hydro-MeOH extract was not the scope of the current study. Despite, it is important to remark that mitochondria function, apart from its role in aerobic energy metabolism, was lately associated with the regulation of myogenesis [77]. Tissue in hypoxic microenvironment and poor oxygen consumption show that satellite cells (SCs) are prone to remain in a state of quiescence whereas an increase in oxidative phosphorylation capacity and production of ATP are associated with SCs activation pro-myogenic events [78]. Importantly, both low-level light biostimulation and phytochemicals present in the S. hispida extract have a role in mitochondria structure and function. One of the causal mechanisms regulating PBMT relies on the fact that light in the NIR spectrum region is absorbed by cytochrome $c$ (unit IV of the mitochondrial electron transport chain) that functions as photoacceptor and photosignal transducer triggering signaling pathways in the course of oxidative phosphorylation and ATP production culminating to a variety of cell events destined to homeostasis recovery $[28,79]$. On the other hand, polyphenol phytochemicals are bioactive compounds with multi-functional role that proactively interferes in the activity and structure of mitochondria.

Gallic acid and quercetin phytochemicals (phenolic and flavonoid compounds, respectively) present in the extract of $S$. hispida aerial parts (see Table 2) might likely have a seminal role in the antiophidic activity against snake 


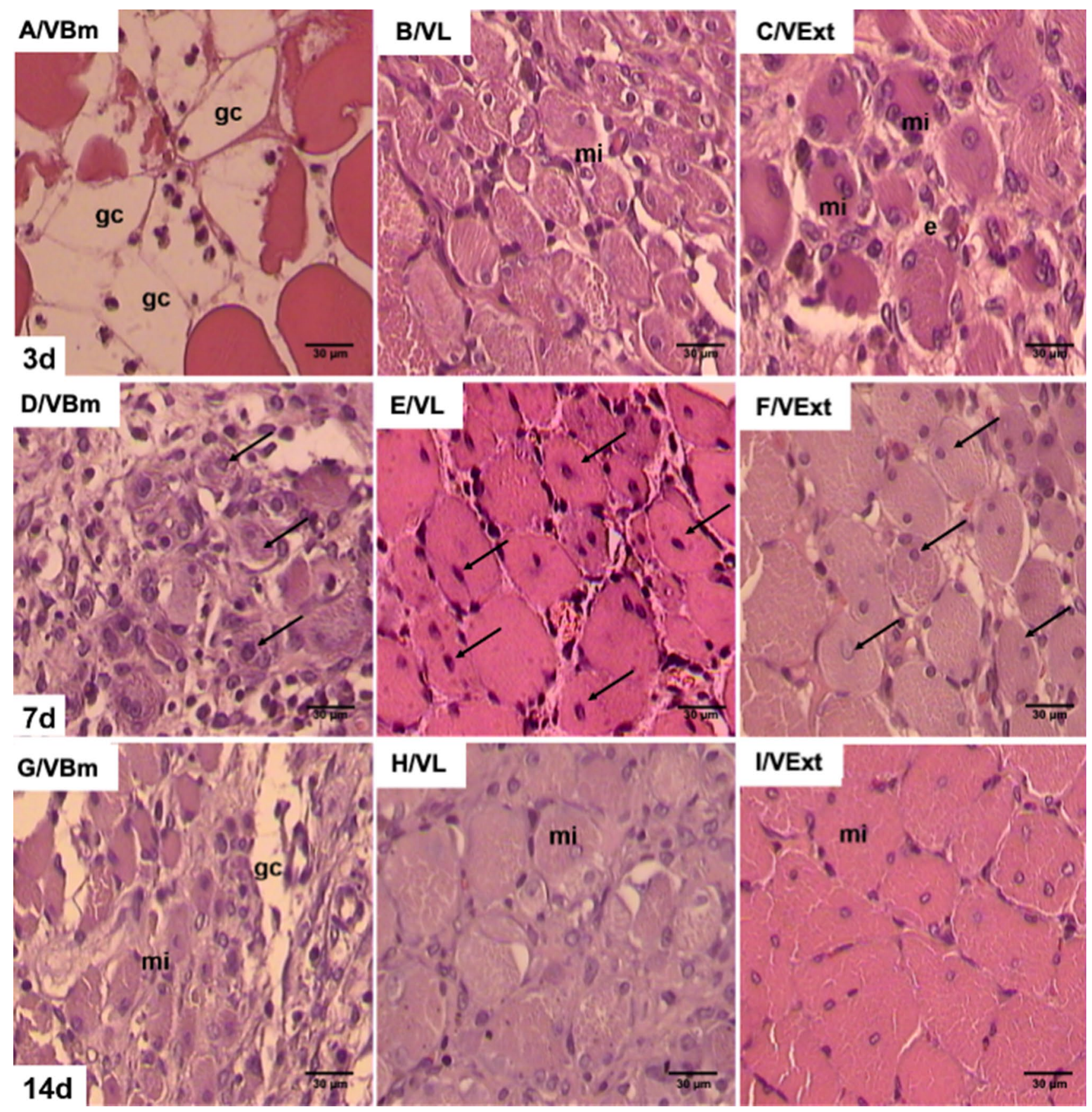

Fig. 4 Light micrographs of rats' gastrocnemius injected with Bothrops moojeni snake venom $(0.4 \mathrm{mg} / \mathrm{kg})$ and exposed to PBMT or $S$. hispida hydro- $\mathrm{MeOH}$ extract. A-C transversal section of the gastrocnemius muscle $(5-\mu \mathrm{m}$-thick) at 3 days after B. moojeni venom injection from VBm (A), VL (B), and VExt (C) groups. D-F transversal section of the gastrocnemius muscle $(5-\mu \mathrm{m}$-thick) at 7 days after B. moojeni venom injection from VBm (D), VL (E), and VExt (F) groups. G-I transversal section of the gastrocnemius muscle (5- $\mu$ m-thick) at 14 days after B. moojeni venom injection from $\mathrm{VBm}$ (G), VL (H), and VExt (I) groups. $g c$ ghost cells; mi myoblasts (including black arrows); $e$ edema. H\&E; scale bar $=30 \mu \mathrm{m}$ venom toxicity, and/or mechanisms to restore homeostasis. Gallic acid was able to inhibit hemorrhage, edema, and the dermonecrotic and myonecrotic activities of Daboia russelii snake venom [80]. Quercetin showed inhibitory action against $\mathrm{PLA}_{2}$ present in the venom of Crotalus durissus terrificus and Naja naja snakes [81, 82]. PLA ${ }_{2}$ is responsible for myotoxicity, edema, inflammation, and hemorrhage after the snakebite [81, 83]. Thus, this background corroborates with our suggestion that the antiophidic potential of S. hispida hydro-MeOH extract is due to the phenolic constituents 

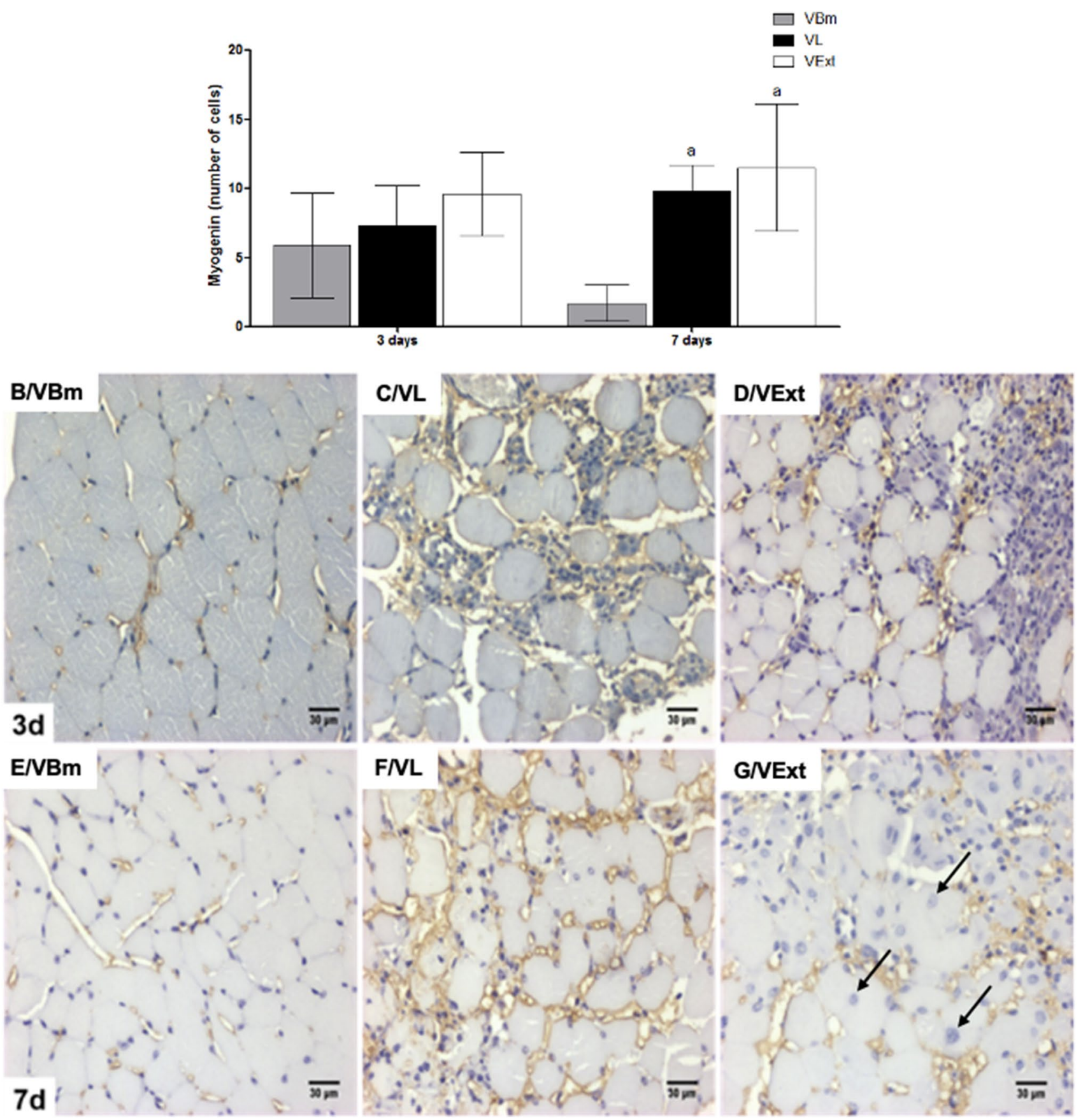

Fig. 5 Myogenin (MyoG) expression in gastrocnemius muscle after Bothrops moojeni venom injection. A number of MyoG immunodetected-cells at 3 and 7 days after B. moojeni venom injection (VBm), or venom plus $S$. hispida extract (VExt), or venom plus GaAs laser irradiation (VL); values represent the average number of immunolabeled cells in 10 histological fields; "a"=significant difference $(p<0.05)$ in comparison to VL group; Kruskal-Wallis followed by

and flavonoids from such extract. The phytochemicals found in the extract of $S$. hispida can scavenge reactive oxygen and nitrogen species produced in the damaged muscle and activate expression of genes related to the antioxidant system,
Dunn post-hoc test; data are expressed as mean \pm SD. B-D immunolabeling of MyoG in myoblasts in proliferation (brown color) the gastrocnemius muscle at 3 days after $B$. moojeni venom injection for VBm (B), VExt (C), and VL (D) groups. E-G immunochemical location of MyoG (brownish) in the gastrocnemius muscle at 7 days after B. moojeni venom injection for VBm (B), VL (C), and VExt (D) groups. Scale bar $=30 \mu \mathrm{m} ; 400 \times$ amplification

members of the anti-apoptotic protein family and pro-survival trophic factors [84]; polyphenols (hydrolysable tannins and phenylpropanoids), including flavonoids as found herein in the S. hispida extract regulate mitochondrial membrane 
permeability and prevent oxidative damage and lipid peroxidation [85].

\section{Conclusions and future perspectives}

We could suggest that PBMT and the S. hispida hydro$\mathrm{MeOH}$ extract succeeded to partially neutralize the hemorrhagic, myotoxic and edematogenic effects that otherwise had been found in untreated muscle exposed to B. moojeni venom. In doing so, both treatments improved the repair process of the muscle damaged area. We suggest that the positive modulation of a series of cellular events already known that are promoted by PBMT underlies muscle regeneration. On the other hand, the major constituents of the aerial parts of S. hispida, gallic acid and quercetin, can likely been correlated with the activity of the plant species in reducing the local effects caused by the bothropic envenoming, being interesting the development of more tests to ensure a better quality, safety and efficacy of the extract. In conclusion, studies on the mechanisms of muscle repair are particularly of interest in myonecrosis settings induced by venomous snakes' accidents, a neglected high incident disease in developing countries.

Author contribution Doroty M. Dourado: Formal Analysis, Investigation, Writing - Original draft preparation, Writing—Review \& Editing. Rosemary Matias: Conceptualization, Methodology, Formal Analysis, Investigation, Resources, Writing-Original draft preparation, Writing-Review \& Editing, Funding Acquisition. Baldomero Antonio Kato da Silva: Methodology, Validation, Formal Analysis, Review \& Editing. Fiorela Faria Milanesi: Investigation. Mayara Duarte Martello: Investigation. Carlos Henrique Marques dos Santos: Investigation. Claudia Andréa Lima Cardoso: Methodology, Formal Analysis, Investigation, Resources, Original draft preparation. Willians Fernando Vieira: Writing — Original draft preparation, Writing—Review \& Editing. Maria Alice da Cruz-Höfling: Conceptualization, Methodology, Writing-Original draft preparation, Writing-Review \& Editing, Supervision, Project Administration, Funding Acquisition.

Funding This work was supported by the São Paulo Research Foundation (FAPESP) (Proc. 05/53625-1) (http://www.fapesp.br/), the Brazilian National Council for Scientific and Technological Development (CNPq, grant nos. 488792/2011 and 486142/2012-4) (http:// www.cnpq.br/), and partially by the University Anhanguera-Uniderp, Campo Grande, MS, Brazil. MACH is a Senior research fellow from CNPq (grant no. 310111/2016-4); RM is granted with a PQ-2 Research Productivity scholarship (grant no. 312142/2019-6).

Availability of data and material Not applicable.

Code availability Not applicable.

\section{Declarations}

Conflict of interest The authors declare no competing financial interests or personal relationships that could have appeared to influence the study reported in this paper.
Ethics approval In vivo experiments were approved by the Institutional Committee for Ethics in Animal Use (CEUA/IB/UNICAMP, protocol number 2757-1).

\section{References}

1. Gutiérrez, J. M., Theakston, R. D. G., \& Warrell, D. A. (2006). Confronting the neglected problem of snake bite envenoming: The need for a global partnership. PLoS Medicine, 3, 727-731. https:// doi.org/10.1371/journal.pmed.0030150

2. Kasturiratne, A., Wickremasinghe, A. R., Silva, N., Gunawardena, N. K., Pathmeswaran, A., Premaratna, R., Savioli, L., Lalloo, D. G., \& Silva, H. J. (2008). The global burden of snakebite: A literature analysis and modelling based on regional estimates of envenoming and deaths. PLoS Medicine, 5, 1591-1604. https:// doi.org/10.1371/journal.pmed.0050218

3. WHO. (2009). Neglected Tropical Diseases: Snakebite. Accessed 25 January 2021. http://www.who.int/neglecteddiseases/diseases/ snakebites/en/index.html

4. Harrison, R. A., Hargreaves, A., Wagstaff, S. C., Faragher, B., \& Lalloo, D. G. (2009). Snake envenoming: A disease of poverty. PLoS Neglected Tropical Diseases, 3, 1-6. https://doi.org/10. 1371/journal.pntd.000056

5. Fan, H. W., \& Cardoso, J. L. (1995). Clinical toxicology of snake bites in South America. In J. Meier \& J. White (Eds.), Handbook of clinical toxicology of animal venoms and poisons (pp. 667-688). CRC Press.

6. Recena, M. C. P., Xavier-Pires, D., \& Caldas, E. D. (2006). Acute poisoning with pesticides in the state of Mato Grosso do Sul, Brazil. Science of the Total Environment, 357, 88-95. https://doi. org/10.1016/j.scitotenv.2005.04.029

7. Aguiar, W. S., Galizio, N. C., Serino-Silva, C., Sant'Anna, S. S., Grego, K. F., Tashima, A. K., Nishiduka, E. S., Morais-Zani, K., \& Tanaka-Azevedo, A. M. (2019). Comparative compositional and functional analyses of Bothrops moojeni specimens reveal several individual variations. PLOS ONE, 14(9), e0222206. https:// doi.org/10.1371/journal.pone.0222206

8. Chippaux, J. P., Williams, V., \& White, J. (1991). Snake venom variability: Methods of study, results and interpretation. Toxicon, 29(11), 1279-1303. https://doi.org/10.1016/0041-0101(91) 90116-9

9. Warrell, D. A. (2010). Snake bite. Lancet, 375, 77-88. https://doi. org/10.1016/S0140-6736(09)61754-2

10. Barros, S. F., Friedlanskaia, I., Petricevich, V. L., \& Kipnis, T. L. (1998). Local inflammation, lethality and cytokine release in mice injected with Botrops atrox venom. Mediators of Inflammation, 7(5), 339-346. https://doi.org/10.1080/09629359890866

11. Hernández Cruz, A., Garcia-Jimenez, S., Zucatelli-Mendonça, R., \& Petricevich, V. L. (2008). Pro- and anti-inflammatory cytokines release in mice injected with Crotalus durissus terrificus venom. Mediators of Inflammation, 2008, 874962. https://doi.org/10. 1155/2008/874962

12. Filippin, L. I., Cuevas, M. J., Lima, E., Marroni, N. P., GonzalezGallego, J., \& Xavier, R. M. (2011). Nitric oxide regulates the repair of injured skeletal muscle. Nitric Oxide, 24(1), 43-49. https://doi.org/10.1016/j.niox.2010.11.003

13. Chargé, S. B. P., \& Rudnicki, M. A. (2004). Cellular and molecular regulation of muscle regeneration. Physiological Reviews, 84(1), 209-238. https://doi.org/10.1152/physrev.00019.2003

14. Battellino, C., Piazza, R., Silva, A. M. M., Cury, Y., \& Farsky, S. H. P. (2003). Assessment of efficacy of bothropic antivenom therapy on microcirculatory effects induced by Bothrops 
jararaca snake venom. Toxicon, 41, 583-593. https://doi.org/ 10.1016/s0041-0101(02)00389-6

15. Fry, B. G., Winkel, K. D., Wickramaratna, J. C., Hodgson, W. C., \& Wüster, W. (2003). Effectiveness snake antivenom: Species and regional venom variation and its clinical impact. Journal of Toxicology, 22, 23-24. https://doi.org/10.1081/TXR120019018

16. Melgarejo, A. F. (2003). Serpentes peçonhentas do Brasil. In J. L. C. Cardoso, F. O. S. França, F. H. Wen, C. M. S. Málaque, \& V. Haddad Jr. (Eds.), Animais peçonhentos no Brasil, biologia, clínica e terapêutica dos acidentes (pp. 33-61). Sarvier Editora.

17. Kenzo-Kagawa, B., Vieira, W. F., Cogo, J. C., \& Cruz-Höfling, M. A. (2020). Muscle proteolysis via ubiquitin-proteasome system

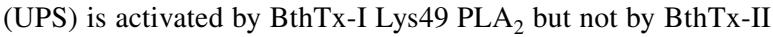
Asp49 $\mathrm{PLA}_{2}$ and Bothrops jararacussu venom. Toxicology and Applied Pharmacology, 402, e115119. https://doi.org/10.1016/j. taap.2020.115119

18. Gutiérrez, J. M. (1995). Clinical toxicology of snakebite in Central America. In J. Meier \& J. White (Eds.), Handbook of clinical toxicology of animal venoms and poisons (pp. 645-665). CRC Press.

19. Borges, C. V., Minatel, I. O., Gomez-Gomez, H. A., \& Lima, G. P. P. (2017). Medicinal plants: Influence of environmental factors on the content of secondary metabolites. Medicinal plants and environmental challenges (pp. 259-277). Springer, Cham.

20. Nazato, V. S., Rubem-Mauro, L., Vieira, N. A. G., Rocha-Junior, D. S., Silva, M. G., Lopes, P. S., Dal-Belo, C. A., Cogo, J. C., Santos, M. G., Cruz-Höfling, M. A., \& Oshima-Franco, Y. (2010). In vitro antiophidian properties of Dipteryx alata vogel bark extracts. Molecules, 15, 5956-5970. https://doi.org/10.3390/ molecules 15095956

21. Giovannini, P., \& Howes, M.-J.R. (2017). Medicinal plants used to treat snakebite in Central America: Review and assessment of scientific evidence. Journal of Ethnopharmacology, 199, 240-256. https://doi.org/10.1016/j.jep.2017.02.011

22. Rai, M. K., Cordell, G. A., Martinez, J. L., Marinoff, M., \& Rastrelli, L. (2012). Medicinal plants: biodiversity and drugs. CRC Press.

23. Dourado, D. M., Silva, A. A. P., Silva, B. A. K., Tozzetti, I. A., Fermiano, M. H., Guilhermino, J. F., \& Matias, R. (2013). Efeito da planta Sebastiana hispida no fígado de ratos injetados com veneno de Bothrops moojeni, correlacionados com marcadores enzimáticos e laser de baixa potência. Revista Fitos, 7, 137-145.

24. Rizzi, E. S., Dourado, D. M., Matias, R., Muller, J. A. I., Guilhermino, J. F., Guerrero, A. T. G., Moreira, D. L., Silva, B. A. K., \& Barbosa-Ferreira, M. (2016). Wound-healing potential of Sebastiania hispida (Mart.) Pax (Euphorbiaceae) ointment compared to low power laser in rats. Brazilian Journal of Biology, 77, 480-489. https://doi.org/10.1590/1519-6984.16115

25. Muller, J. A. I., Matias, R., Guilhermino, J. F., Lima-Moreira, D., Santos, K. S., Fermiano, M. H., Silva, B. A. K., \& Dourado, D. M. (2018). The effect of Sebastiania hispida gel on wound model infected by methicillin resistant Staphylococcus aureus. Biomedicine \& Pharmacotherapy, 105, 1311-1317. https://doi. org/10.1016/j.biopha.2018.06.100

26. Kandolf-Sekulovic, L., Katarano-Vski, M., \& Pavlovic, M. D. (2003). Imunomodulatory effects of low intensity near infrared laser irradiation on contact hypersensitivity reaction. Journal of Photochemistry and Photobiology, 19, 203-212. https://doi.org/ 10.1034/j.1600-0781.2003.00040.x

27. Vladimirov, Y. A., Osipov, A. N., \& Klebanov, G. I. (2004). Photobiological principles of therapeutic applications of laser radiation. Biochemistry (Moscow), 69, 81-90. https://doi.org/10.1023/b:biry. $0000016356.93968 .7 \mathrm{e}$

28. De Freitas, L. F., \& Hamblin, M. R. (2016). Proposed mechanisms of photobiomodulation or low-level light therapy. IEEE Journal of
Selected Topics in Quantum Electronics, 22(3), 7000417. https:// doi.org/10.1109/JSTQE.2016.2561201

29. Vieira, W. F., Magalhães, S. F., Farias, F. H., Thomaz, A. A., \& Parada, C. A. (2019). Raman spectroscopy of dorsal root ganglia from streptozotocin-induced diabetic neuropathic rats submitted to photobiomodulation therapy. Journal of Biophotonics, 12, e201900135. https://doi.org/10.1002/jbio.201900135

30. Doin-Silva, R., Baranauskas, V., Rodrigues-Simioni, L., \& CruzHöfling, M. A. (2009). The ability of low-level laser therapy to prevent muscle tissue damage induced by snake venom. Photochemistry and Photobiology, 85, 63-69. https://doi.org/10.1111/j. 1751-1097.2008.00397.x

31. Dourado, D. M., Fávero, S., Baranauskas, V., \& Cruz-Höfling, M. A. (2003). Effects of the Ga-As laser irradiation on myonecrosis caused by Bothrops moojeni snake venom. Lasers in Surgery and Medicine, 33, 352-357. https://doi.org/10.1002/lsm.10237

32. Dourado, D. M., Fávero, M., Carvalho, P. T. C., \& Cruz-Höfling, M. A. (2011). Low-level laser therapy promotes vascular endothelial growth factor receptor-1 expression in endothelial and nonendothelial cells of mice gastrocnemius exposed to snake venom. Photochemistry and Photobiology, 87, 418-426. https://doi.org/ 10.1111/j.1751-1097.2010.00878.x

33. Dourado, D. M., Matias, R., Barbosa-Ferreira, M., Silva, B. A. K., Muller, J. A. I., Vieira, W. F., \& Cruz-Höfling, M. A. (2017). Effects of photobiomodulation therapy on Bothrops moojeni snake-envenomed gastrocnemius of mice using enzymatic biomarkers. Lasers in Medical Science, 32, 1357-1366. https://doi. org/10.1007/s10103-017-2252-4

34. Nadur-Andrade, N., Barbosa, A. M., Carlos, F. P., Lima, C. J., Cogo, J. C., \& Zamunér, S. R. (2012). Effects of photobiostimulation on edema and hemorrhage induced by Bothrops moojeni venom. Lasers in Medical Science, 27, 65-70. https://doi.org/10. 1007/s10103-011-0914-1

35. Sousa, A. P. C., Paraguassú, G. M., Silveira, N. T. T., Souza, J., Cangussú, M. C. T., Santos, J. N., \& Pinheiro, A. L. B. (2013). Laser and LED phototherapies on angiogenesis venom. Lasers in Medical Science, 28, 981-987. https://doi.org/10.1007/ s10103-012-1187-z

36. Vieira, W. F., Kenzo-Kagawa, B., Cogo, J. C., Baranauskas, V., \& Cruz-Höfling, M. A. (2016). Low-level laser therapy (904 nm) counteracts motor deficit of mice hind limb following skeletal muscle injury caused by snakebite-mimicking intramuscular venom injection. PLoS ONE, 11, 1-17. https://doi.org/10.1371/ journal.pone.0158980

37. Vieira, W. F., Kenzo-Kagawa, B., Britto, M. H. M., Ceragioli, H. J., Sakane, K. K., Baranauskas, V., \& Cruz-Höfling, M. A. (2018). Vibrational spectroscopy of muscular tissue intoxicated by snake venom and exposed to photobiomodulation therapy. Lasers in Medical Science, 33, 503-512. https://doi.org/10.1007/ s10103-017-2389-1

38. Silva, L. M. G., Zamuner, L. F., David, A. C., Santos, S. A., Carvalho, P. T. C., \& Zamuner, S. R. (2018). Photobiomodulation therapy on bothrops snake venom-induced local pathological effects: A systematic review. Toxicon, 152, 23-29. https://doi. org/10.1016/j.toxicon.2018.07.006

39. Harborne, A. B. (1998). Phytochemical methods: a guide to modern techniques of plant analysis. Springer.

40. Fontoura, F. M., Matias, R., Ludwig, J., de Oliveira, A. K. M., Bono, J. A. M., Martins, P. F. R. B., Corsino, J., \& Guedes, N. M. R. (2015). Seasonal effects and antifungal activity from bark chemical constituents of Sterculia apetala (Malvaceae) at Pantanal of Miranda, Mato Grosso do Sul, Brazil. Acta Amazonica, 45, 283-292. https://doi.org/10.1590/1809-4392201500011

41. BRASIL. (2010). Farmacopéia Brasileira $6^{\mathrm{a}}$ ed. Brasília: Agência Nacional de Vigilância Sanitária, 546 p. http://www.anvisa.gov. br/hotsite/cd_farmacopeia/index.htm. Accessed 29 April 2020. 
42. Folin, O., \& Ciocalteu, V. (1927). On tyrosine and tryptophane determinations in proteins. Journal of Biological Chemistry, 73(2), 627-650. https://doi.org/10.1016/S0021-9258(18)84277-6

43. Do, Q. D., Angkawijaya, A. E., Tran-Nguyen, P. L., Huynh, L. H., Soetaredjo, F. E., Ismadji, S., \& Ju, Y.-H. (2014). Effect of extraction solvent on total phenol content, total flavonoid content, and antioxidant activity of Limnophila aromatica. Journal of Food and Drug Analysis, 22, 296-302. https://doi.org/10.1016/j.jfda. 2013.11.001

44. Bladt, S., \& Zgainski, E. M. (2009). Plant drug analysis: A thin layer chromatography atlas (2nd ed., p. 384). Springer-Verlag.

45. Bae, J. Y., Avula, B., Zhao, J., Raman, V., Wang, Y. H., Wang, M., Zulfiqar, F., Feng, W., Park, J. H., Abe, N., Ali, Z., \& Khan, I. A. (2020). Analysis of prenylflavonoids from aerial parts of Epimedium grandiflorum and dietary supplements using HPTLC, UHPLC-PDA and UHPLC-QToF along with chemometric tools to differentiate Epimedium species. Journal of Pharmaceutical and Biomedicine, 77, 112843. https://doi.org/10.1016/j.jpba.2019. 112843

46. Mester, E., Mester, A. F., \& Mester, A. (1985). The biomedical effects of laser application. Lasers in Surgery and Medicine, 5, 31-39. https://doi.org/10.1002/lsm.1900050105

47. Basford, J. R. (1993). Laser therapy: Scientific basis and clinical role. Orthopedics, 16, 541-547. PMID: 8327381.

48. Basford, J. R. (1995). Low intensity laser therapy: Still not an established clinical tool. Lasers in Surgery and Medicine, 16, 331-342. https://doi.org/10.1002/lsm.1900160404

49. Verma, N., \& Shukla, S. (2015). Impact of various factors responsible for fluctuation in plant secondary metabolites. Journal of Applied Research on Medicinal and Aromatic Plants, 2(4), 105113. https://doi.org/10.1016/j.jarmap.2015.09.0022214-7861

50. Zamunér, S. R., \& Teixeira, C. F. (2002). Cell adhesion molecules involved in the leukocyte recruitment induced by venom of the snake Bothrops jararaca. Mediators of Inflammations, 11(6), 351-357. https://doi.org/10.1080/0962935021000051548

51. Gutiérrez, J. M., \& Ownby, C. L. (2003). Skeletal muscle degeneration induced by venom phospholipases A2: Insights into the mechanisms of local and systemic myotoxicity. Toxicon, 42, 915931. https://doi.org/10.1016/j.toxicon.2003.11.005

52. Gutiérrez, J. M., Rucavado, A., Escalante, T., Herrera, C., Fernández, J., Lomonte, B., \& Fox, J. W. (2018). Unresolved issues in the understanding of the pathogenesis of local tissue damage induced by snake venoms. Toxicon, 15, 123-131. https://doi.org/10.1016/j. toxicon.2018.04.016

53. Rochkind, S., \& Shainberg, A. (2007). Muscle response to complete peripheral nerve injury: Changes of acetylcholine receptor and creatine kinase activity over time. Journal of Reconstructive Microsurgery, 33, 352-357. https://doi.org/10.1055/s-0037-15986 19

54. Hawkins, D., \& Abrahamse, P. (2006). Effect of multiple exposure of low-level laser therapy on the cellular responses of wounded human skin fibroblasts. Photomedicine and Laser Surgery, 24, 705-714. https://doi.org/10.1089/pho.2006.24.705

55. Huang, Y.-Y., Karma, S. K., Carroll, J., \& Hamblin, M. R. (2011). Biphasic dose response in low level light therapy-an update. Dose-Response, 9, 602-618. https://doi.org/10.2203/dose-respo nse.11-009.Hamblin

56. Pereañez, J. A., Núñez, V., Patiño, A. C., Londoño, M., \& Quintana, J. C. (2011). Inhibitory effects of plant phenolic compounds on enzymatic and cytotoxic activities induced by a snake venom phospholipase A2. Vitae, 18, 295-304.

57. Vale, L. H. F., Mendes, M. M., Fernandes, R. S., Costa, T. R., Hage-Melim, L. I. S., Sousa, M. A., Hamaguchi, A., HomsiBrandeburgo, M. I., Franca, S. C., Silva, C. H., Pereira, P. S., Soares, A. M., \& Rodrigues, V. M. (2011). Protective effect of Schizolobium parahyba flavonoids against snake venoms and isolated toxins. Current Topics in Medicinal Chemistry, 11, 2566-2577. https://doi.org/10.2174/156802611797633438

58. Santhosh, M. S., Hemshekhar, M., Sunitha, K., Thushara, R. M., Jnaneshwari, S., Kemparaju, K., \& Girish, K. S. (2013). Snake venom induced local toxicities: Plant secondary metabolites as an auxiliary therapy. Mini Reviews in Medicinal Chemistry., 13, 106-123. PMID: 22876950.

59. Santhosh, M. S., Hemshekhar, M., Thushara, R. M., Devaraja, S., Kemparaju, K., \& Girish, K. S. (2013). Vipera russelli venominduced oxidative stress and hematological alterations: Amelioration by crocin a dietary colorant. Cell Biochemistry and Function, 31(1), 41-50. https://doi.org/10.1002/cbf.2858

60. Gómez-Betancur, I., Gogineni, V., Salazar-Ospina, A., \& León, F. (2019). Perspective on the therapeutics of anti-snake venom. Molecules, 24, 3276. https://doi.org/10.3390/molecules24183276

61. Nishioka, S. A., \& Silveira, P. V. (1992). A clinical and epidemiologic study of 292 cases of lance-headed viper bite in Brazilian teaching hospital. American Journal of Tropical Medicine and Hygiene, 47, 805-810. https://doi.org/10.4269/ajtmh.1992.47.805

62. Lomonte, B., \& Gutiérrez, J. M. (2011). Phospholipases A2 from viperidae snake venoms: How do they induce skeletal muscle damage? Acta Chimica Slovenica, 58, 647-659. PMID: 24061112.

63. Martin, R. (2003). Low level laser therapy (LLLT) precipitates a complex set of physiological interactions at the cellular level that reduces acute inflammation, reduces pain, and accelerates tissue healing. Practical Pain Management, 3, 1-4.

64. Karu, T. I., Afanasyeva, N. I., Kolyakov, S. F., Pyatibrat, L. V., \& Welser, L. (2001). Changes in absorbance of monolayer of living cells induced by laser radiation at 633,670 , and $820 \mathrm{~nm}$. IEEE Journal of Selected Topics in Quantum Electronics, 7, 982-988. https://doi.org/10.1109/2944.983303

65. Lubart, R., Friedmann, H., \& Lavie, R. (2000). Photobiostimulation as a function of different wavelengths. Journal of Laser Therapy, 12, 38-41. https://doi.org/10.5978/islsm.12.38

66. Stadler, I., Evans, R., Kolb, B., Naim, J. O., Narayan, V., Buehner, N., \& Lanzafame, R. J. (2000). In vitro effects of low-level laser irradiation at $660 \mathrm{~nm}$ on peripheral blood lymphocytes. Lasers in Surgery and Medicine, 27, 255-261. https://doi.org/10.1002/ 1096-9101(2000)27:3\%3c255::aid-1sm7\%3e3.0.co;2-1

67. Silva, O. C., Jr., Zucoloto, S., Menegazzo, L. A., Granato, R. G., Marcassa, L. G., \& Bagnato, V. S. (2001). Laser enhancement in hepatic regeneration for partially hepatectomized rats. Lasers in Surgery and Medicine, 29, 73-77. https://doi.org/10.1002/1sm. 1089

68. Garavello-Freitas, I., Baranauskas, V., Joazeiro, P. P., Padovani, C. R., Silva, M.D.-P., \& Cruz-Höfling, M. A. (2003). Low-power laser irradiation improves histomorphometrical parameters and bone matrix organization during tibia wound healing in rats. Journal of Photochemistry and Photobiology B: Biology, 70, 81-89. https://doi.org/10.1016/s1011-1344(03)00058-7

69. Strauch, M. A., Tomaz, M. A., Monteiro-Machado, M., Ricardo, H. D., Cons, B. L., Fernandes, F. F. A., El-Kik, C. Z., Azevedo, M. S., \& Melo, P. A. (2013). Antiophidic activity of the extract of the Amazon plant Humirianthera ampla and constituents. Journal of Ethnopharmacology, 145, 50-58. https://doi.org/10.1016/j.jep. 2012.10.033

70. Reis, F. P., Bonfa, I. M. S., Cavalcante, R. B., Okoba, D., Vasconcelos, S. B. S., Candeloro, L., Filiu, W. F. O., Monreal, A. C. D., Silva, V. J., Rita, P. H. S., Carollo, C. A., \& Toffoli-Kadri, M. C. (2014). Tabebuia aurea decreases inflammatory, myotoxic and hemorrhagic activities induced by the venom of Bothrops neuwiedi. Journal of Ethnopharmacology, 158, 352-357. https:// doi.org/10.1016/j.jep.2014.10.045

71. Fernandes, J. M., Félix-Silva, J., Cunha, L. M., Gomes, J. A. S., Siqueira, E. M. S., Gimenes, L. P., Lopes, N. P., Soares, L. A. L., Fernandes-Pedrosa, M. P., \& Zucolotto, S. M. (2016). Inhibitory 
effects of hydroethanolic leaf extracts of Kalanchoe brasiliensis and Kalanchoe pinnata (Crassulaceae) against local effects induced by Bothrops jararaca snake venom. PLoS ONE, 11, 1-20. https://doi.org/10.1371/journal.pone.0168658

72. Felix-Silva, J., Silva-Junior, A. A., Zucolotto, S. M., \& FernandesPedrosa, M. F. (2017). Medicinal plants for the treatment of local tissue damage induced by snake venoms: An overview from traditional use to pharmacological evidence. Evidence-Based Complementary and Alternative Medicine. https://doi.org/10.1155/2017/ 5748256

73. Bahramsoltani, R., Farzaei, M. H., \& Rahimi, R. (2014). Medicinal plants and their natural components as future drugs for the treatment of burn wounds: An integrative review. Archives of Dermatological Research, 306, 601-617. https://doi.org/10.1007/ s00403-014-1474-6

74. Scur, M. C., Pinto, F. G. S., Pandini, J. A., Costa, W. F., Leite, C. W., \& Temponi, L. G. (2016). Antimicrobial and antioxidant activity of essential oil and different plant extracts of Psidium cattleianum Sabine. Brazilian Journal of Biology, 76, 101-108. https://doi.org/10.1590/1519-6984.13714

75. Meadows, E., Cho, J.-H., Flynn, J. M., \& Klein, W. H. (2008). Myogenin regulates a distinct genetic program in adult muscle stem cells. Developmental Biology, 322, 406-414. https://doi.org/ 10.1016/j.ydbio.2008.07.024

76. Ferri, P., Barbieri, E., Burattini, S., Guescini, M., D’Emilio, A., Biagiotti, L., Grande, P. D., De Luca, A., Stocchi, V., \& Falcieri, E. (2009). Expression and subcellular localization of myogenic regulatory factors during the differentiation of skeletal muscle C2C12 myoblasts. Journal of Cellular Biochemistry, 108, 13021317. https://doi.org/10.1002/jcb.22360

77. Khacho, M., \& Slack, R. S. (2017). Mitochondrial activity in the regulation of stem cell self-renewal and differentiation. Current Opinion in Cell Biology, 49, 1-8. https://doi.org/10.1016/j.ceb. 2017.11.003

78. Abreu, P., \& Kowaltowski, A. (2020). Satellite cell self-renewal in endurance exercise is mediated by inhibition on mitochondrial oxygen consumption. Journal of Cachexia, Sarcopenia and Muscle, 11(6), 1661-1676. https://doi.org/10.1002/jcsm.12601

79. Karu, T. I., Pyatibrat, L. V., Kolyakov, S. F., \& Afanasyeva, N. I. (2005). Absorption measurements of a cell monolayer relevant to phototherapy: Reduction of cytochrome c oxidase under near IR radiation. Journal of Photochemistry and Photobiology B: Biology, 81, 98-106. https://doi.org/10.1016/j.jphotobiol.2005.07.002

80. Mahadeswaraswamy, Y. H., Kumar, M. S., Gowtham, Y. J., Nagaraju, S., Girish, K. S., \& Kemparaju, K. (2011). The polyphenol 3,4,5-tri-hydroxybenzoic acid inhibits indian Daboia russelli venom and its hemorrhagic complex induced local toxicity. Current Topics in Medicinal Chemistry, 11, 2520-2530. https://doi. org/10.2174/156802611797633447

81. Cotrim, C. A., Oliveira, S. C. B., Diz Filho, E. B. S., Fonseca, F. V., Baldissera, L., Jr., Antunes, E., Ximenes, R. M., Monteiro, H. S. A., Rabello, M. M., Hernandes, M. Z., Toyama, D. O., \& Toyama, M. H. (2011). Quercetin as an inhibitor of snake venom secretory phospholipase A2. Chemico-Biological Interactions, 189, 9-16. https://doi.org/10.1016/j.cbi.2010.10.016

82. Gopi, K., Anbarasu, K., Renu, K., Jayanthi, S., Vishwanath, B. S., \& Jayaraman, G. (2016). Quercetin-3-O-rhamnoside from Euphorbia hirta protects against snake venom induced toxicity. Biochimica et Biophysica Acta, 1860, 1528-1540. https://doi.org/ 10.1016/j.bbagen.2016.03.031

83. Urs, N. A. N., Yariswamy, M., Joshi, V., Nataraju, A., Gowda, T. V., \& Vishwanath, B. S. (2014). Implications of phytochemicals in snakebite management: Present status and future prospective. Toxin Reviews, 33, 60-83. https://doi.org/10.3109/15569543. 2013.854255

84. Naoi, M., Wu, Y., Shamoto-Nagai, M., \& Maruyama, W. (2019). Mitochondria in neuroprotection by phytochemicals: Bioactive polyphenols modulate mitochondrial apoptosis system, function and structure. International Journal of Molecular Sciences, 20(10), 2451. https://doi.org/10.3390/ijms20102451

85. Veiko, A. G., Sekowski, S., Lapshina, E. A., Wilczewska, A. Z., Markiewicz, K. H., Zamaraeva, M., Zhao, H.-C., \& Zavodnik, I. B. (2020). Flavonoids modulate liposomal membrane structure, regulate mitochondrial membrane permeability and prevent erythrocyte oxidative damage. Biochimica et Biophysica Acta, Biomembranes, 1862(11), 183442. https://doi.org/10.1016/j.bbamem. 2020.183442

\section{Authors and Affiliations}

\section{Doroty Mesquita Dourado ${ }^{1,2,8}\left([) \cdot\right.$ Rosemary Matias $^{3}\left(\mathbb{C}^{\circ} \cdot\right.$ Baldomero Antonio Kato da Silva $^{4}(\mathbb{D}$. Fiorela Faria Milanesi ${ }^{5}$ (1) - Mayra Duarte Martello ${ }^{6}$. Carlos Henrique Marques dos Santos ${ }^{1}$ (D) Claudia Andréa Lima Cardoso ${ }^{7}$ (i) - Willians Fernando Vieira ${ }^{8}$ (D) Maria Alice da Cruz-Höfling ${ }^{8}$ (i)}

\author{
Doroty Mesquita Dourado \\ douradod@uol.com.br \\ Rosemary Matias \\ rosematiasc@gmail.com \\ Fiorela Faria Milanesi \\ fiorelamilanesi@gmail.com \\ Mayra Duarte Martello \\ mayra.martello@educadores.net.br \\ Carlos Henrique Marques dos Santos \\ chenriquems@yahoo.com.br \\ Claudia Andréa Lima Cardoso \\ claudiacardosouems1@gmail.com \\ Willians Fernando Vieira \\ williansfvieira@gmail.com
}

Maria Alice da Cruz-Höfling

hofling@unicamp.br

1 Laboratory of Toxicology and Medicinal Plants, Anhanguera-Uniderp University, Campo Grande, MS, Brazil

2 Postgraduate Program in Infectious and Parasitic Diseases, Federal University of Mato Grosso do Sul (UFMS), Campo Grande, MS, Brazil

3 Postgraduate Program in Environment and Regional Development, Anhanguera-Uniderp University, Campo Grande, MS, Brazil

4 Postgraduate Program in Biomedical Sciences, Federal University of Delta do Parnaíba (UFDPar), Av. São Sebastião 2819, Parnaíba, PI 64202-020, Brazil 
5 Health and Environment: Biodiversity Program at Oswaldo Cruz Foundation MS, Campo Grande, MS, Brazil

6 Postgraduate Program in Biochemistry and Molecular Biology, Federal University of Mato Grosso do Sul (UFMS), Campo Grande, MS, Brazil
7 Department of Chemistry, Mato Grosso do Sul State University (UEMS), Dourados, MS, Brazil

8 Department of Structural and Functional Biology, Institute of Biology, University of Campinas (UNICAMP), Campinas, SP, Brazil 